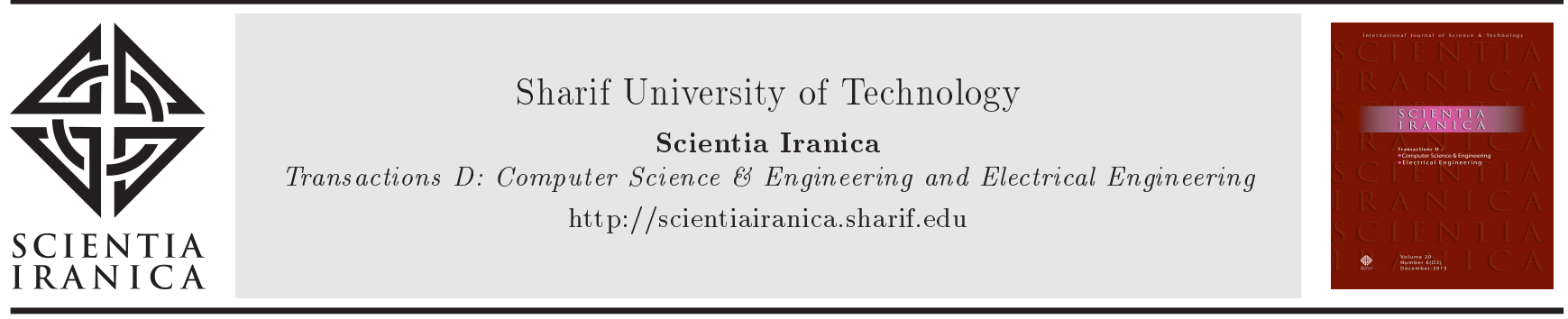

\title{
Symbiotic organisms search algorithm for economic load dispatch problem with valve-point effect
}

\author{
U. Guvenc ${ }^{a}$, S. Duman ${ }^{a, *}$, Y. Sonmez ${ }^{b}$, H. Tolga Kahraman ${ }^{\text {, }}$, and \\ M. Kenan Dosoglu \\ a. Department of Electrical and Electronics Engineering, Technology Faculty, Duzce University, Duzce, Turkey. \\ b. Department of Electrical Technology, Gazi Vocational College, Gazi University, Ankara, Turkey. \\ c. Department of Software Engineering, Faculty of Technology, Karadeniz Technical University, Trabzon, Turkey.
}

Received 18 August 2015; received in revised form 7 April 2016; accepted 16 January 2017

KEYWORDS
Symbiotic organisms
search;
Economic load
dispatch;
Power systems;
Optimization.

\section{Introduction}

Economic Load Dispatch (ELD) is one of the most popular and important optimization problems in modern power system operation and aims to minimize the total cost of function scheduling outputs of all generating units to meet the load demand while satisfying some equality and inequality system constraints. ELD becomes a highly non-linear optimization problem when the valve-point effects, multi-fuel effects, etc. are considered. Therefore, solving this non-smooth optimization problem and finding the global optimum become very difficult.

\footnotetext{
*. Corresponding author.

E-mail addresses: ugurguvenc@duzce.edu.tr (U. Guvenc); serhatduman@duzce.edu.tr (S.Duman);

ysonmez@gazi.edu.tr (Y. Sonmez);

htolgakahraman@ktu.edu.tr (H. Tolga Kahraman);

kenandosoglu@duzce.edu.tr (M. Kenan Dosoglu)
}

doi: $10.24200 /$ sci.2017.4378
Researchers have made great efforts to solve the ELD problem from past to the present. Classical methods like linear programming [1], interior point [2,3], and dynamic programming [4] were used in early times. In order to overcome some drawbacks of these algorithms, including insecure convergence properties, long execution time, and algorithmic complexity, many meta-heuristic based optimization algorithms were developed and proposed to solve ELD. Simulated Annealing (SA) was implemented [5] in ELD problems and produced nearly optimal solutions in the early 1990s. Then, evolutionary based algorithms were used for solving ELD problem. Genetic Algorithm (GA) [6] and its improved versions [7] were also widely used. Tabu Search (TS) [8], Particle Swarm Optimization (PSO) [9,10], Differential Evolution (DE) [11], Ant Colony Optimization (ACO) [12,13], Bacterial Foraging Optimization (BFO) [14], Artificial Bee Colony algorithm (ABC) [15], Gravitational Search Algorithm (GSA) [16], Biogeography-Based Optimization (BBO) [17], Improved Mutative Scale Chaos Opti- 
mization Algorithm (IMSCOA) [18], Pattern Search method (PS) [19], Seeker Optimization Algorithm (SOA) [20], Taguchi Method (TM) [21], Modified Shuffled Frog Leaping Algorithm (MSFLA) [22], and Firefly Algorithm (FA) [23] are other heuristic search algorithms applied to ELD in course of finding the best optimal solution. Besides hybrid algorithms such as Cultural Self-Organizing Migrating Algorithm (CSOMA) [24], Chaotic Differential Evolution and Quadratic Programming (DEC-SQP) [25], Fuzzy Adaptive Particle Swarm Optimization (FAPSO) [26], hybrid Genetic Algorithm approach based on Differential Evolution (GA-DE) [27], hybrid populationbased algorithm (PSOGSA) [28], Genetic Algorithm with Active Power Optimization based on Newton's second order approach (GA-APO) [29], combination of Modified Subgradient and Harmony Search (MSGHS) [30], hybrid Shuffled Differential Evolution (SDE) algorithm [31,32], Improved Coordinated Aggregationbased Particle Swarm Optimization (ICA-PSO) [33], integrated Particle Swarm Optimization technique with the Sequential Quadratic Programming (PSOSQP) technique [34], modified hybrid Particle Swarm Optimization and GSA based on fuzzy logic (FPSOGSA) [35], Real parameter Quantum Evolutionary Algorithm (RQEA) [36], etc. have been developed by authors to solve ELD problem. Even though all of these algorithms produce good solutions and have some advantages, each method has its own drawbacks. As it is declared in [37], SA suffers from slow convergence and its parameter determination is difficult, PSO has a slow fine-tuning ability of solution and it has difficulty in escaping from the local optimum, GA's offspring production capacity is weak and it shows slow convergence near the best optimal solution, and TS is inefficient in describing effective memory structures and strategies adequate for the problem.

Symbiotic Organisms Search algorithm (SOS) is a brand new and effective metaheuristic optimization algorithm developed by Cheng and Prayogo [38] in 2014. It is an improved algorithm for finding the best possible solution to optimization problems with multi-variable functions and simulates symbiotic interaction tactics used by organisms in order to survive in the nature. Because SOS is an algorithm for a newborn, no studies have been applied to different areas. However, Cheng and Prayogo examined it on 26 different benchmark functions and structural design optimization problems in order to show the effectiveness of the algorithm. Then, they compared its performance with other optimization algorithms such as GA, DE, PSO, Bees Algorithm (BA), Mine Blast Algorithm (MBA), and Cuckoo Search (CS). According to results, it was seen that SOS produced better results than others in all cases. Therefore, SOS algorithm is chosen to search the globally optimum solution and investigate the produced results for ELD problem with valve-point effect in this paper. ELD solution, which is performed using SOS, is examined over standard power systems including IEEE 3-machine 6-bus, IEEE 5-machine 14-bus, IEEE 6-machine 30-bus, and 13- and 40-unit test systems both with transmission loss and without transmission loss. The results are compared with those reported in the literature; they show that SOS algorithm produces better solutions than other algorithms to the ELD problem.

The rest of the paper is organized as follows: problem formulation is described in Section 2. SOS algorithm and its application to ELD problem are explained in Section 3. Experimental results are given in Section 4 and, finally, Section 5 presents conclusions.

\section{Problem formulation}

ELD is the most common and most important nonlinear optimization problem in power system operation and management. The aim of ELD is to meet the load demand while satisfying some equality and inequality system constraints by scheduling the generator outputs. Outputs of generators having multi-valve steam turbines should be increased by opening the valves when an increase occurs in load demand. But, this process creates ripples on heat rate curve of generating units and sinusoidal components on their power outputs. Thus, nonlinear feature of ELD problem increases. Hence, reaching the solution to this problem becomes difficult due to increase in local optimum points in the search space [35]. When the valve-point effect is taken into account, the ELD problem can be described as follows:

$$
\begin{aligned}
\min f= & \min \sum_{k=1}^{N} F_{k}\left(P_{k}\right), \\
F_{k}\left(P_{k}\right)= & a_{k}+b_{k} P_{k}+c_{k} P_{k}^{2} \\
& +\left|d_{k} \times \sin \left(e_{k} \times\left(P_{k}^{\min }-P_{k}\right)\right)\right|,
\end{aligned}
$$

where $F_{k}\left(P_{k}\right)$ is total generation cost of unit $k ; a_{k}$, $b_{k}$, and $c_{k}$ are cost coefficients; $d_{k}$ and $e_{k}$ are cost coefficients with valve-point effect of unit $k$; and $P_{k}$ is the power output of unit $k$. The ELD problem described in Eq. (2) is subject to constraints, which are power balance and ramp rate limits. According to the power system constraints, the power generation of total system is equal to the sum of total system load $\left(P_{d}\right)$ and total power loss $\left(P_{l s}\right)$. It can be described as follows:

$$
\sum_{k=1}^{N} P_{k}=P_{d}+P_{l s},
$$

where $P_{l s}$ can be calculated by using $B$-coefficients as follows: 


$$
P_{l s}=\sum_{k=1}^{N} \sum_{l=1}^{N} P_{k} B_{k l} P_{l}+\sum_{k=1}^{N} B_{0 k} P_{k}+B_{00}
$$

where $B_{k l}$ is the $k, l$-th elements of loss coefficient square matrix, $B_{0 k}$ is the $k$-th vector of matrix, and $B_{00}$ is the constant of loss coefficient.

The second constraint is ramp rate limits. According to this, the power output of each generating unit is limited with a minimum value and a maximum one.

$$
P_{k}^{\min } \leq P_{k} \leq P_{k}^{\max }
$$

\subsection{Computing for slack generator}

According to this calculation method, active power load of first $(N-1)$ generating units is defined when $N$ units generate power subject to the power balance equality given in Eq. (1). In this instance, the power output of $N$ th unit (i.e., slack generator) can be described as follows $[17,35]$ :

$$
P_{N}=P_{d}+P_{l s}-\sum_{k=1}^{(N-1)} P_{k}
$$

where $P_{l s}$ is a function of all outputs of generating units comprising the slack generator and it can be described as follows:

$$
\begin{aligned}
P_{l s}= & \sum_{k=1}^{N-1} \sum_{l=1}^{N-1} P_{k} B_{k l} P_{l}+2 P_{N}\left(\sum_{k=1}^{N-1} B_{N k} P_{k}\right) \\
& +B_{N N} P_{N}^{2}+\sum_{k=1}^{N-1} B_{0 k} P_{k}+B_{0 N} P_{N}+B_{00}
\end{aligned}
$$

Eq. (6) becomes Eq. (8) by expanding and rearranging as follows:

$$
\begin{aligned}
B_{N N} P_{N}^{2} & +\left(2 \sum_{i=1}^{N-1} B_{N i} P_{G i}+B_{0 N}-1\right) P_{N} \\
& +\left(P_{D}+\sum_{i=1}^{N-1} \sum_{j=1}^{N-1} P_{G i} B_{i j} P_{G j}\right. \\
& \left.+\sum_{i=1}^{N-1} B_{0 i} P_{G i}-\sum_{i=1}^{N-1} P_{G i}+B_{00}\right)=0 .
\end{aligned}
$$

Eq. (8) can be calculated via standard algebraic methods and, thus, the loading of the dependent generation unit (i.e., $N$ th) can be found. In order to achieve this, the following simplifications can be used:

$$
\begin{aligned}
& \alpha P_{N}^{2}+\beta P_{N}+\delta=0, \\
& \alpha=B_{N N}, \\
& \beta=\left(2 \sum_{k=1}^{N-1} B_{N k} P_{k}+B_{0 N}-1\right),
\end{aligned}
$$

$$
\begin{aligned}
\delta= & \left(P_{d}+\sum_{k=1}^{N-1} \sum_{l=1}^{N-1} P_{k} B_{k l} P_{l}+\sum_{k=1}^{N-1} B_{0 k} P_{k}\right. \\
& \left.-\sum_{k=1}^{N-1} P_{k}+B_{00}\right) .
\end{aligned}
$$

The positive roots of the equation give output of the slack generator to satisfy Eq. (6) and it can be found as follows:

$$
P_{N}=\frac{-\beta \mp \sqrt{\Delta}}{2 \alpha}
$$

where $\Delta=\beta^{2}-4 \alpha \delta \geq 0$.

\section{Symbiotic Organisms Search (SOS) algorithm and application to the ELD problem}

The SOS algorithm is a population-based stochastic technique developed by Cheng and Prayogo [38] in 2014. It iteratively uses a population of candidate solutions to the optimization of nonlinear functions at multi-dimensional space in the process of seeking the optimal global solution.

SOS consists in a group of organisms in ecosystem. It simulates the interactive behavior seen among organisms in ecosystem. There is a reliance-based relationship between the organisms, which is known as symbiosis. Symbiosis includes relationships that are mutualistic, parasitic, or commensal and is used to describe a relationship between any two distinct organisms. The symbiotic relationships are performed by applying special operators, namely, mutualism, commensalism, and parasitism. Mutualism represents a symbiotic relationship between two different species in which each individual benefits from the activity of the other. Commensalism is a symbiotic relationship between two different species in which one organism benefits from the other without affecting it. Parasitism is a non-mutual symbiotic relationship between two different species in which one species, the parasite, benefits at the expense of the other, the host. Organisms use symbiotic relationships to adapt to changes in their environment. Thanks to the special operators, fitness and survival advantage of organisms may increase.

In the SOS algorithm, an initial population, called the ecosystem, is firstly created. The ecosystem consists in a group of organisms generated randomly in the search space. Every organism in the ecosystem is a potential solution to the problem and has a certain fitness value, which points out the degree of adaptation to the desired objective. General flowchart of the SOS algorithm is given in Figure 1.

Now, application of SOS algorithm to ELD problem is described below step by step according to the flowchart of the algorithm. 


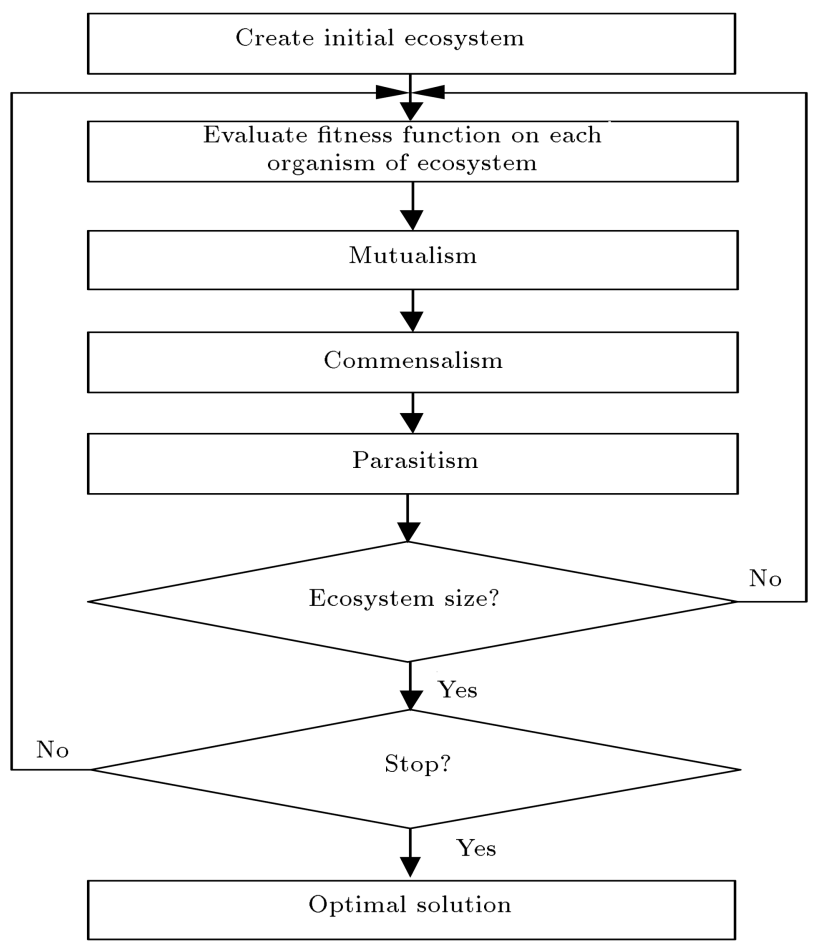

Figure 1. General flowchart of SOS execution.

Step 1. Create initial ecosystem: The ecosystem is created in three steps. In the first step, organisms are created. For every organism, a vector (random values for attributes) is generated in the second step. In the last step, ecosystem parameters, number of organisms (eco_size), and maximum iteration (maxiter) are determined. Figure 2 shows the ecosystem and organisms.

Step 2. Evaluate fitness function of each organism in ecosystem: Depending on values of attributes $\left(\left[a_{1}, a_{2}, a_{3}, \ldots, a_{m}\right]\right.$ is given in Figure 2$)$, the fitness value $\left(\left[f_{\text {value }}\right]\right)$ of each organism is determined by a fitness function. The information on fitness value of an organism is used to search for the fittest organism.

\section{Step 3. Determine mutualism operator:}

a. An organism is selected randomly from ecosystem, $X_{j}$, where $X_{j} \neq X_{i}$., through the following codes;

$$
\begin{aligned}
& \text { /*j=i; } \\
& \text { while } i==j \\
& \quad \text { seed }=\text { randperm }(\text { ecosize }) \\
& \quad j=\operatorname{seed}(1) ; \\
& \text { end } * /
\end{aligned}
$$

b. Mutual relationship vector (Mutual_Vector) and benefit factors (the value of 1 or 2 is assigned randomly to both $\mathrm{BF}_{1}$ and $\mathrm{BF}_{2}$ ) are determined.

c. Mutual_Vector $=\left(X_{i}+X_{j}\right) / 2$.

d. Organisms $X_{i}$ and $X_{j}$ are modified based on their mutual relationship by using Eqs. (12) and (13):

$$
\begin{aligned}
X_{\text {inew }}= & X_{i}+\operatorname{rand}(0,1) \\
& *\left(X_{\text {best }}-\right.\text { Mutual } \\
\text { Vector } & \left.* B F_{1}\right), \\
X_{\text {jnew }}= & X_{j}+\operatorname{rand}(0,1) \\
& *\left(X_{\text {best }}-\right.\text { Mutual } \\
\text { Vector } & \left.* B F_{2}\right) .
\end{aligned}
$$

e. Fitness values of $X_{\text {inew }}$ and $X_{\text {jnew }}$ are calculated. If the modified organisms are fitter than the previous ones, then the modifications are accepted. Otherwise, the modifications are rejected and the previous organisms kept.

Step 4. Determine commensalism operator:

a. An organism is selected randomly from ecosystem, $X_{j}$, where $X_{j} \neq X_{i}$.

b. Organism $X_{j}$ is used to modify organism $X_{i}$ by using Eq. (14):

$$
X_{\text {inew }}=X_{i}+\operatorname{rand}(-1,1) *\left(X_{\text {best }}-X_{j}\right) .
$$

c. Fitness value of $X_{\text {inew }}$ is calculated. If the

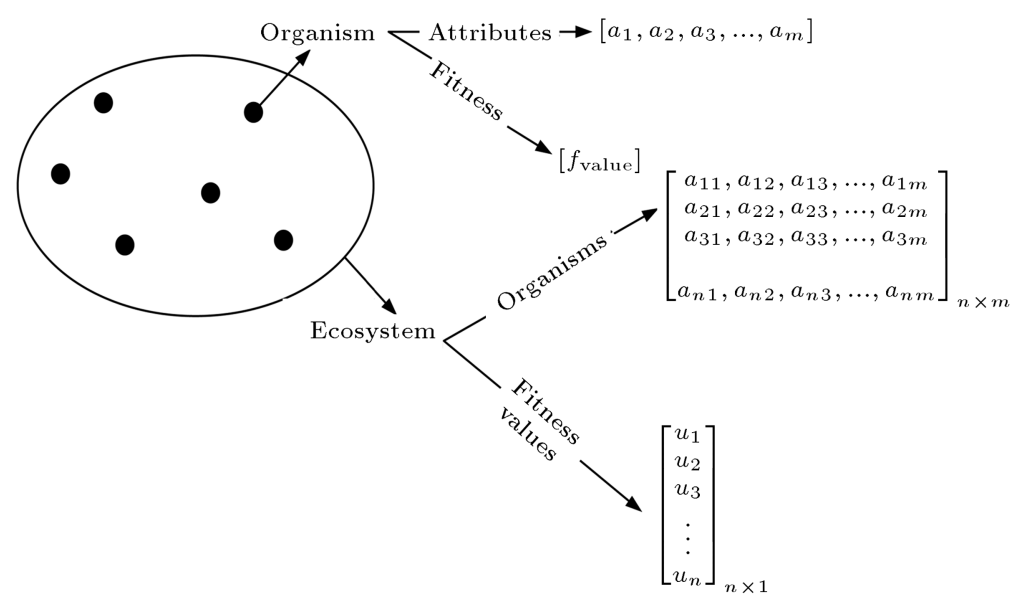

Figure 2. Representation of ecosystem and organisms. 


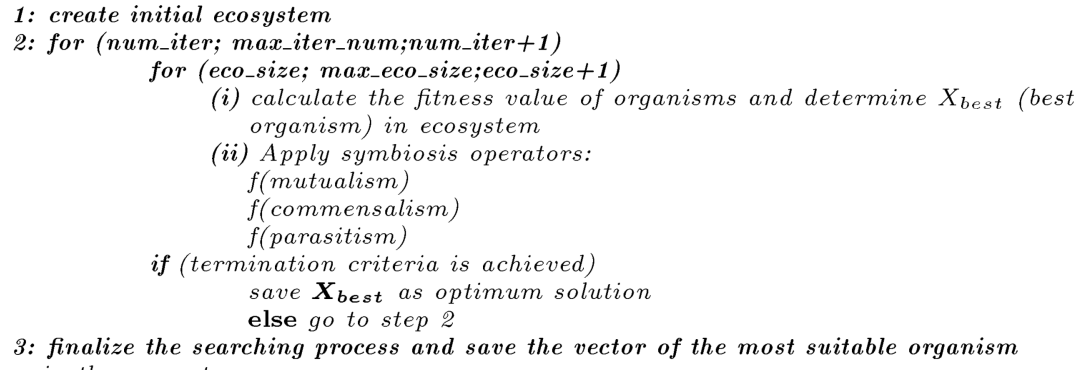

Figure 3. The pseudocode of SOS algorithm to search the optimum solution.

modified organism is fitter than the previous one, then the new organism is accepted to replace $X_{i}$. Otherwise, the modification is rejected and the previous organism kept $\left(X_{i}\right)$.

Step 5. Determine parasitism operator:

a. An organism is selected randomly from ecosystem, $X_{j}$, where $X_{j} \neq X_{i}$.

b. A parasite vector (Parasite_Vector) is created from organism $X_{i}$.

c. Fitness value of $X_{i}$ is calculated. If the fitness value of Parasite_Vector is fitter than $X_{j}$, then organism $X_{j}$ is replaced with Parasite_Vector. Otherwise, replacement operation is performed, $X_{j}$ kept, and Parasite_Vector deleted.

Step 6. Determine ecosystem size: It is the number of organisms in ecosystem. Each organism is a potential solution to the problem at hand. The population size in genetic algorithm and the number of bees in a colony in artificial bee colony algorithm are also known.

Step 7. Stop: Termination criteria are determined to stop the optimization process. If one of the termination criteria is reached, then the $X_{\text {best }}$ is saved as optimum solution; otherwise, we return to Step 2 and start the next iteration.

The pseudocode developed for SOS algorithm is given in Figure 3.

\subsection{Implementation of SOS algorithm for ELD problem}

This section introduces the step-wise procedure for implementing SOS algorithm to solve non-convex ELD problem with valve-point effects while satisfying both equality and inequality constraints. The process and computational producer of the SOS algorithm are laid out as follows:

- Representation of the ecosystem: The aim in ELD problems is to determine the most suitable generator output power. Because generator output values form this in optimization variables, they are used to represent molecules in an organism. Thus, an organism is represented in the form of the following matrix:

$$
X=\left[M_{1}, M_{2}, M_{3}, \ldots, M_{n}\right],
$$

where $M$ is the molecule and $n$ is the total number of generators. Each organism is a possible solution to the non-convex ELD problem with valve-point effects. Finally, the ecosystem is created by the combination of all organisms. An ecosystem is represented as follows:

$$
E=\left[\begin{array}{c}
X_{1} \\
X_{2} \\
X_{3} \\
\vdots \\
X_{m}
\end{array}\right]
$$

$m$ is the number of organisms.

- Problem parameters identification: The number of generator units, maximum and minimum capacities of each generator, power demand, $B$-coefficients matrix for calculation of transmission losses, and fuel cost function coefficients are specified. Also, the SOS parameters, like number of organisms and maximum iteration number, are determined.

- Ecosystem initialization: For initialization, the initial molecule is defined by generating a uniform random number between lower and upper limits for the related generator power output as follows:

$$
M_{i}=P_{i}^{\min }+\operatorname{rand}(0,1) *\left(P_{i}^{\max }-P_{i}^{\min }\right) .
$$

The ecosystem is obtained by applying this operation to all molecules making up each organism.

- Calculation and evaluation of fitness function for each organism of ecosystem: FC represents the fuel cost of all generators in the test system for the power demand. Calculated fuel costs for an ecosystem are represented as follows: 


$$
F C_{e c o}=\left[\begin{array}{c}
F C_{1} \\
F C_{2} \\
F C_{3} \\
\vdots \\
F C_{m}
\end{array}\right] .
$$

Here, $F C_{1}$ shows the fitness value of the first organism of ecosystem. The organism with the minimum fuel cost value in the ecosystem is chosen as the best organism ( $X$ is signified with best).

- Mutualism, commensalism, and parasitism phases: New organisms are obtained through operations as indicated in SOS algorithm. The organisms obtained here represent a better solution to the non-convex ELD problem with valve-point effects.

- If the termination criteria are not reached, the next iteration is started.

- The end.

\section{Experimental results}

The SOS algorithm has been used for solving the ELD problem with valve-point effect. Five different test systems are used to show effectiveness of the proposed method. They are IEEE 3-machine 6-bus, IEEE 5machine 14-bus, IEEE 6-machine 30-bus, and 13- and 40-unit test systems both with transmission loss and without transmission loss. The setting parameters of the proposed heuristic technique are given in Appendix Table A.1 in the Appendix. The program is written in MATLAB and run on a $2.63 \mathrm{GHz}$ Pentium IV personal computer with 512MB RAM. Descriptions of the test systems are given as follows:
- Test Case 1: IEEE 3-machine 6-bus test system is considered in this case. The generators data are obtained from [29] and presented Tables A.2 and A.3 in the Appendix. The load demand of all units with $210 \mathrm{MW}$ should be satisfied. The proposed method is run 40 times and the obtained results are illustrated in Table 1 by comparison with other methods reported before. Minimum, average, and maximum results of the proposed method and comparison with the results obtained from the other methods in the literature are shown in Table 2.

The convergence curve of the total fuel cost obtained from SOS algorithm for Test Case 1 is shown in Figure 4. According to Figure 4, the SOS algorithm reaches the optimal solution in about 25 iterations. This result shows that the SOS algorithm

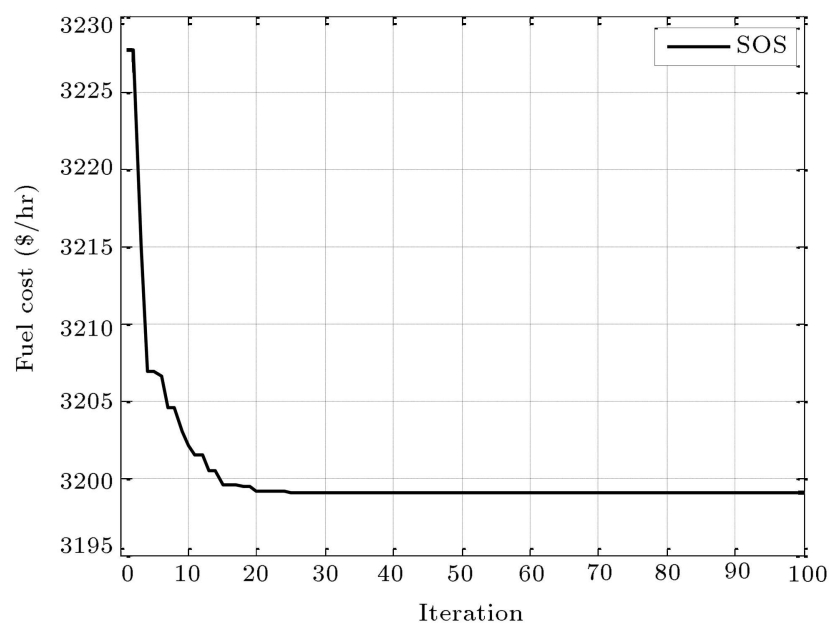

Figure 4. Convergence of total fuel cost obtained from SOS for Test Case 1.

Table 1. Comparison of the results obtained from SOS for Test Case 1.

\begin{tabular}{ccccc}
\hline & \multicolumn{4}{c}{ Methods } \\
\cline { 2 - 5 } Units & GA [29] & GA-APO [29] & NSOA [29] & SOS \\
\hline$P_{1}$ & 53.2604 & 61.6467 & 50 & 50 \\
$P_{2}$ & 88.9645 & 95.1632 & 86.0356 & 76.0015 \\
$P_{3}$ & 74.7693 & 60.5402 & 79.7438 & 90.8627 \\
Total power output (MW) & 216.9942 & 217.3501 & 215.7794 & $\mathbf{2 1 6 . 8 6 4 2}$ \\
Total fuel cost $(\$ / \mathrm{hr})$ & 3252.4576 & 3341.771 & 3206.0022 & $\mathbf{3 1 9 9 . 0 1 1 3}$ \\
$P_{\text {loss }}(\mathrm{MW})$ & 6.9939 & 7.346085 & 5.7794 & $\mathbf{6 . 8 6 4 1}$ \\
Simulations times of the SOS algorithm (s) & & & & $\mathbf{8 . 2 5 8 7}$ \\
\hline
\end{tabular}

Table 2. The results obtained from the SOS for Test Case 1.

\begin{tabular}{cccc}
\hline Method & Min. & Average & Max. \\
\hline GA [29] & 3252.46 & - & 3463.37 \\
GA-APO [29] & 3341.77 & - & 3294.81 \\
NSOA [29] & 3205.99 & - & 3206.00 \\
SOS & $\mathbf{3 1 9 9 . 0 1 1 3}$ & $\mathbf{3 1 9 9 . 0 1 1 3}$ & $\mathbf{3 1 9 9 . 0 1 1 3}$ \\
\hline
\end{tabular}




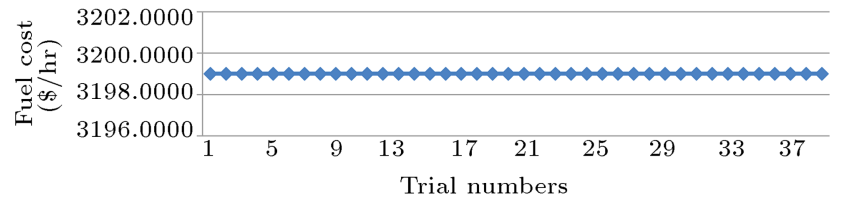

Figure 5. The total fuel cost values obtained from the SOS algorithm for 40 trials (Test Case 1).

converges on the solution quickly. As can be seen in Table 1, optimal solution of SOS for this test case is less than the best solution reported in [29] by $6.99 \$ / \mathrm{hr}$. Besides, minimum, average, and maximum results of SOS algorithm have the same value for 40 runs. This result shows that SOS algorithm produces very accurate and fast results in all trials for small power systems. The total fuel cost values obtained from the proposed approach for the solutions performed 40 times for Test Case 1 are shown in Figure 5.

Test Case 2: IEEE 5-machine 14-bus test system is considered in this case. The total load demand is $259 \mathrm{MW}$. The generators data are obtained from [29] and presented in Tables A.2 and A.3. The proposed algorithm is run 40 times and the results obtained from it are presented in Table 3 by comparison with other methods reported before in the literature. According to the results in Table 3, the proposed algorithm produces the minimum fuel cost with $834.1302 \$ / \mathrm{hr}$ and it is obviously seen that this result is the best among all in the literature. The convergence curve of total fuel cost obtained from SOS for this case is illustrated in Figure 6. The SOS algorithm reaches the optimal solution in about 55 iterations as seen in Figure 6. The minimum, average, and maximum results of the SOS method and results obtained from the other heuristic techniques previously reported in the literature for this test system are given in Table 4 . The total fuel cost values obtained from the proposed SOS algorithm

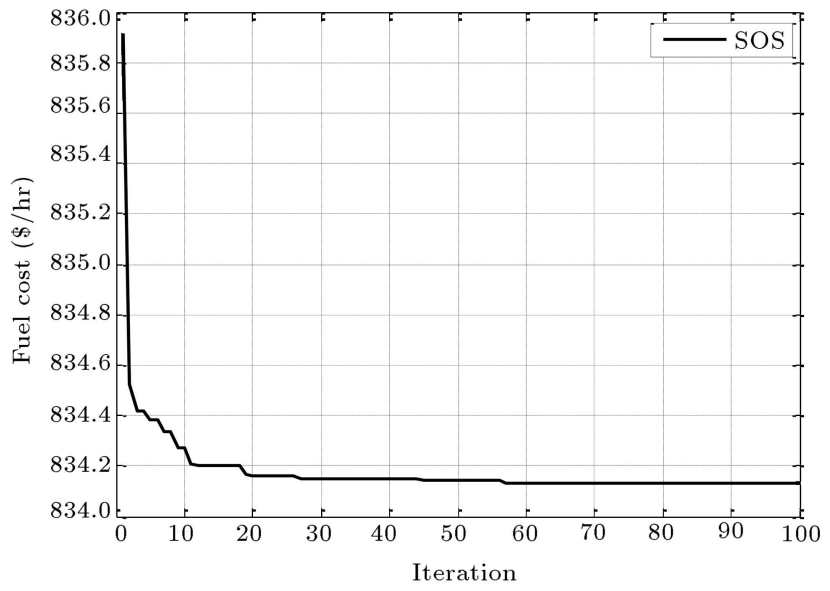

Figure 6. Convergence of total fuel cost obtained from SOS for Test Case 2.

Table 4. The results obtained from the proposed approach for Test Case 2.

\begin{tabular}{cccc}
\hline Method & Min. & Average & Max. \\
\hline GA [29] & 926.5530 & - & 1012.44 \\
GA-APO [29] & 926.5530 & - & 960.55 \\
NSOA [29] & 905.5437 & - & 906.63 \\
PSO [30] & 836.4568 & 834.969 & 837.716 \\
MSG-HS [30] & 834.363 & 834.673 & 836.119 \\
FPSOGSA [35] & 834.1308 & 834.1312 & 834.1337 \\
SOS & $\mathbf{8 3 4 . 1 3 0 2}$ & $\mathbf{8 3 4 . 1 3 1 0}$ & $\mathbf{8 3 4 . 1 3 3 1}$ \\
\hline
\end{tabular}

in the solutions done 40 times for Test Case 2 are shown in Figure 7. From Figure 7, it is obvious that the total fuel cost values have been changed by 0.0029 unit.

- Test Case 3: IEEE 6-machine 30-bus test system is considered in this case. The total load demand is 283.4 MW for this case. The generators data are obtained from [29,35] and presented in Tables A.2 and A.3. Results are obtained from the proposed

Table 3. Comparison of the results obtained from SOS for Test Case 2.

\begin{tabular}{|c|c|c|c|c|c|c|c|}
\hline \multirow[b]{2}{*}{ Units } & \multicolumn{7}{|c|}{ Methods } \\
\hline & $\begin{array}{l}\text { GA } \\
{[29]}\end{array}$ & $\begin{array}{c}\text { GA-APO } \\
{[29]}\end{array}$ & $\begin{array}{c}\text { NSOA } \\
{[29]}\end{array}$ & $\begin{array}{c}\text { PSO } \\
{[30]}\end{array}$ & $\begin{array}{c}\text { MSG-HS } \\
{[30]}\end{array}$ & $\begin{array}{c}\text { FPSOGSA } \\
{[35]}\end{array}$ & SOS \\
\hline$P_{1}$ & 172.7647 & 172.7647 & 181.1287 & 197.4696 & 199.6923 & 199.5997 & 199.5997 \\
\hline$P_{2}$ & 26.6212 & 26.6212 & 46.7567 & 20.0000 & 20.0000 & 20.0000 & 20.0000 \\
\hline$P_{3}$ & 24.8322 & 24.8322 & 19.1526 & 21.3421 & 20.8157 & 20.9133 & 20.9913 \\
\hline$P_{4}$ & 23.4152 & 23.4152 & 10.1879 & 11.6762 & 15.5504 & 15.4893 & 15.4673 \\
\hline$P_{5}$ & 19.1885 & 19.1885 & 10.7719 & 17.7744 & 12.5069 & 12.5527 & 12.4960 \\
\hline Total power output (MW) & 266.8217 & 266.8217 & 267.9977 & 268.2623 & 268.5653 & 268.555 & 268.5543 \\
\hline Total fuel cost $(\$ / \mathrm{hr})$ & 926.5530 & 926.5530 & 905.5437 & 836.4568 & 834.363 & 834.1308 & 834.1302 \\
\hline$P_{\text {loss }}(\mathrm{MW})$ & 7.8250 & 7.8250 & 8.9977 & 9.2623 & 9.5654 & 9.555 & 9.5543 \\
\hline Simulations times of the SOS algorithm (s) & & & & & & & 14.7816 \\
\hline
\end{tabular}




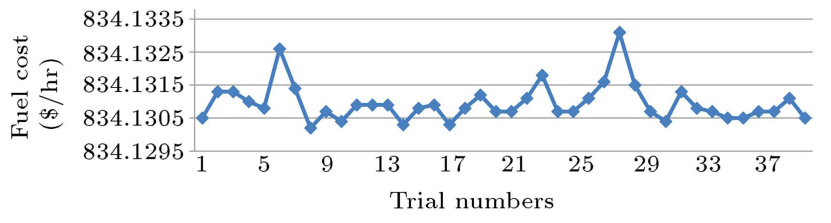

Figure 7. The total fuel cost values obtained from the SOS algorithm for 40 trials (Test Case 2).

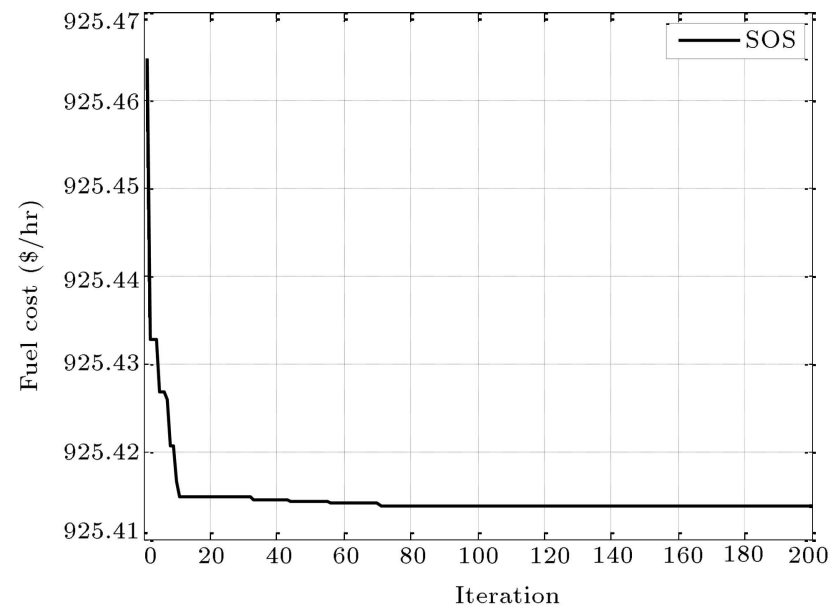

Figure 8. Convergence of total fuel cost obtained from SOS for Test Case 3.

algorithm for 40 runs and given in Table 5 by comparison with other techniques reported before in the literature. The SOS algorithm has the same value for total fuel cost of $925.4137 \$ / \mathrm{hr}$ and it is less than others reported before. Moreover, the proposed algorithm meets the total load demand exactly, but FPSOGSA misses with a little difference. Thus, SOS is a good alternative method to solve such a power system. The convergence curve of total fuel cost for this case is presented in Figure 8. The proposed algorithm converges on the global optima after about 70 iterations as seen in Figure 8. The
Table 6. The results obtained from the proposed approach for Test Case 3.

\begin{tabular}{cccc}
\hline Method & Min & Average & Max \\
\hline GA[29] & 996.0369 & - & 1117.13 \\
GA-APO [29] & 1101.491 & - & 996.04 \\
NSOA [29] & 984.9365 & - & 992.48 \\
PSO [30] & 925.7581 & 926.388 & 928.427 \\
MSG-HS [30] & 925.6406 & 926.851 & 928.599 \\
FPSOGSA [35] & 925.4137 & 925.4175 & 925.4213 \\
SOS & 925.4137 & 925.4143 & 925.4197 \\
\hline
\end{tabular}

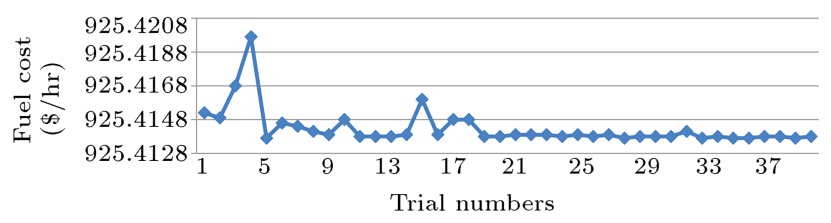

Figure 9. The total fuel cost values obtained from the SOS method for 40 trials (Test Case 3 ).

minimum, average, and maximum results of the SOS method and results obtained from the other stochastic methods in the literature for this test system are given in Table 6 . The total fuel cost values obtained from the proposed SOS algorithm for the solutions done 40 times for Test Case 3 are shown in Figure 9. From Figure 9, it is clear that the total fuel cost values are changed by 0.0060 unit.

- Test Case 4: IEEE 13-machine test system is considered in this case. Three different load demands, namely, $1800 \mathrm{MW}$ and $2520 \mathrm{MW}$ with transmission loss and $2520 \mathrm{MW}$ constrained, are considered. In the constrained case, power outputs of the 11th and 12th generators are fixed at $75 \mathrm{MW}$ and $60 \mathrm{MW}$. Generators data and $B$-coefficient are

Table 5. Comparison of the results obtained from SOS for Test Case 3.

\begin{tabular}{|c|c|c|c|c|c|c|c|}
\hline \multirow[b]{2}{*}{ Units } & \multicolumn{7}{|c|}{ Methods } \\
\hline & $\begin{array}{l}\text { GA } \\
{[29]}\end{array}$ & $\begin{array}{c}\text { GA-APO } \\
{[29]}\end{array}$ & $\begin{array}{c}\text { NSOA } \\
{[29]} \\
\end{array}$ & $\begin{array}{c}\text { PSO } \\
{[30]} \\
\end{array}$ & $\begin{array}{c}\text { MSG-HP } \\
{[30]} \\
\end{array}$ & $\begin{array}{c}\text { FPSOGSA } \\
{[35]}\end{array}$ & SOS \\
\hline$P_{1}$ & 150.724 & 133.9816 & 182.478 & 197.8648 & 199.6331 & 199.5997 & 199.5997 \\
\hline$P_{2}$ & 60.8707 & 37.2158 & 48.3525 & 50.3374 & 20.0000 & 20.0000 & 20.0000 \\
\hline$P_{3}$ & 30.8965 & 37.7677 & 19.8553 & 15.0000 & 23.7624 & 23.9896 & 23.9768 \\
\hline$P_{4}$ & 14.2138 & 28.3492 & 17.1370 & 10.0000 & 18.3934 & 18.8493 & 18.8679 \\
\hline$P_{5}$ & 19.4888 & 18.7929 & 13.6677 & 10.0000 & 17.1018 & 18.2153 & 18.2212 \\
\hline$P_{6}$ & 15.9154 & 38.0525 & 12.3487 & 12.0000 & 15.6922 & 13.8506 & 13.8402 \\
\hline Total power output (MW) & 292.1096 & 294.1600 & 293.8395 & 295.2022 & 294.5829 & 294.5045 & 294.5058 \\
\hline Total fuel cost $(\$ / \mathrm{hr})$ & 996.0369 & 1101.491 & 984.9365 & 925.7581 & 925.6406 & 925.4137 & 925.4137 \\
\hline $\mathrm{P}_{\text {loss }}(\mathrm{MW})$ & 8.7060 & 10.7563 & 10.4395 & 11.8022 & 11.1830 & 11.1044 & 11.1058 \\
\hline Simulations times of the SOS algorithm (s) & & & & & & & 21.5872 \\
\hline
\end{tabular}


obtained from [35] and presented in Tables A.4 and A.5 in the Appendix. Results obtained from SOS algorithm for these cases are given in Table 7 by comparing other methods reported before. The SOS has the lowest total fuel costs by $18134.2805 \$ / \mathrm{hr}$ and $24515.2275 \$ / \mathrm{hr}$ for $1800 \mathrm{MW}$ and $2520 \mathrm{MW}$ load demands, respectively. The convergence curves for these cases are shown in Figures 10 and 11. It is seen from these figures that for both load demands, the SOS algorithm converges on the global optima after about 20 iterations. The total fuel cost values obtained from the proposed SOS algorithm in the solutions done 40 times for Test Case 4 are shown in Figures 12 and 13. From Figures 12 and 13, it is apparent that the total fuel cost values are changed by 0.1924 and 0.1857 unit, respectively.

Results obtained from SOS algorithm for $2520 \mathrm{MW}$ constrained case are presented in Table 8. According to this table, SOS produces the best result together with FPSOGSA among all methods and has the lowest fuel cost with $24252.9363 \$ / \mathrm{hr}$. The convergence curve of fuel cost for this case is also shown in Figure 14.

- Test Case 5: IEEE 40-machine test system without

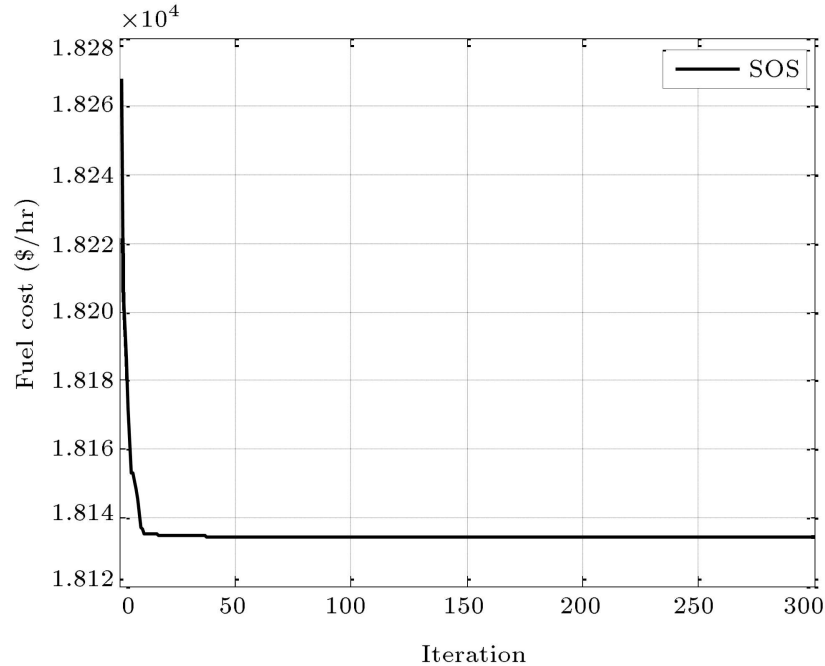

Figure 10. Convergence of total fuel cost obtained from SOS for $1800 \mathrm{MW}$ load demand.

loss is considered in this case. Total load demand is $10500 \mathrm{MW}$. Generators data are taken from [35, 39] and can be observed in the mentioned studies. Results obtained from the proposed algorithm are given in Table 9 and compared with other results ob-

Table 7. Comparison of the results obtained from SOS for $1800 \mathrm{MW}$ and $2520 \mathrm{MW}$ load demands.

\begin{tabular}{|c|c|c|c|c|c|c|c|}
\hline \multirow[b]{3}{*}{ Unit } & \multicolumn{7}{|c|}{ Output power (MW) } \\
\hline & \multicolumn{3}{|c|}{$P_{D}=1800 \mathrm{MW}$} & \multicolumn{4}{|c|}{$P_{D}=2520 \mathrm{MW}$} \\
\hline & SDE [31] & FPSOGSA [35] & SOS & SDE [31] & ICA-PSO [33] & FPSOGSA [35] & SOS \\
\hline$P_{1}$ & 448.80 & 448.7990 & 448.7990 & 628.32 & 628.32 & 628.3185 & 628.3184 \\
\hline$P_{2}$ & 297.93 & 297.9312 & 296.8851 & 299.20 & 299.19 & 299.1993 & 299.199 \\
\hline$P_{3}$ & 223.30 & 223.3374 & 224.3995 & 299.20 & 294.51 & 299.1993 & 299.1992 \\
\hline$P_{4}$ & 109.85 & 109.8666 & 109.8666 & 159.73 & 159.73 & 159.7331 & 159.7331 \\
\hline$P_{5}$ & 109.85 & 109.8666 & 109.8665 & 159.73 & 159.73 & 159.7331 & 159.7329 \\
\hline$P_{6}$ & 159.71 & 159.7331 & 159.7331 & 159.73 & 159.73 & 159.7331 & 159.7331 \\
\hline$P_{7}$ & 109.86 & 109.8666 & 109.8665 & 159.73 & 159.73 & 159.7331 & 159.7331 \\
\hline$P_{8}$ & 60.00 & 60.0000 & 60.0000 & 159.73 & 159.73 & 159.7331 & 159.733 \\
\hline$P_{9}$ & 109.82 & 109.8666 & 109.8665 & 159.73 & 159.73 & 159.7331 & 159.7331 \\
\hline$P_{10}$ & 40.00 & 40.0000 & 40.0000 & 77.40 & 114.80 & 76.9368 & 77.3988 \\
\hline$P_{11}$ & 40.00 & 40.0000 & 40.0000 & 113.12 & 116.45 & 114.2795 & 113.4981 \\
\hline$P_{12}$ & 55.00 & 55.0000 & 55.0000 & 92.40 & 55.00 & 92.2438 & 92.3998 \\
\hline$P_{13}$ & 55.00 & 55.0000 & 55.0000 & 92.40 & 92.40 & 92.2007 & 92.3997 \\
\hline $\begin{array}{l}\text { Total power } \\
\text { output (MW) }\end{array}$ & 1819.13 & 1819.2671 & 1819.2828 & 2560.43 & 2559.05 & 2560.7765 & 2560.8113 \\
\hline$P_{\text {loss }}(\mathrm{MW})$ & 19.13 & 19.2669 & 19.2829 & 40.43 & 39.05 & 40.7765 & 40.8112 \\
\hline $\begin{array}{c}\text { Total fuel } \\
\text { cost }(\$ / \mathrm{hr})\end{array}$ & 18134.49 & 18134.39457 & 18134.2805 & 24514.88 & 24540.06 & 24515.35543 & 24515.2275 \\
\hline $\begin{array}{l}\text { Average fuel } \\
\text { cost }(\$ / \mathrm{hr})\end{array}$ & 18138.56 & 18136.96721 & 18134.2977 & 24516.31 & 24561.46 & 24516.68231 & 24515.2626 \\
\hline \multicolumn{3}{|c|}{ Simulation times of the SOS algorithm (s) } & 45.7831 & \multicolumn{3}{|c|}{ Simulation times of the SOS algorithm (s) } & 45.6429 \\
\hline
\end{tabular}


U. Guvenc et al./Scientia Iranica, Transactions D: Computer Science \& .. 25 (2018) 3490-3506

Table 8. Comparison of the results obtained from SOS for 2520 MW constrained load demand.

\begin{tabular}{|c|c|c|c|c|c|c|c|}
\hline Unit & $\begin{array}{c}\text { EP-SQP } \\
{[34]}\end{array}$ & $\begin{array}{c}\text { PSO-SQP } \\
{[34]}\end{array}$ & $\begin{array}{c}\text { ICA-PSO } \\
{[33]}\end{array}$ & $\begin{array}{c}\text { RQEA } \\
{[36]}\end{array}$ & $\begin{array}{c}\text { SDE } \\
{[32]}\end{array}$ & $\begin{array}{c}\text { FPSOGSA } \\
{[35]}\end{array}$ & SOS \\
\hline$P_{1}$ & 628.3136 & 628.3205 & 628.32 & 628.3170 & 628.31853071796 & 628.3185 & 628.3185 \\
\hline$P_{2}$ & 299.1715 & 299.0524 & 299.20 & 299.1991 & 299.1990034188 & 299.1993 & 299.1993 \\
\hline$P_{3}$ & 299.0474 & 298.9681 & 291.90 & 299.1990 & 299.19930034189 & 299.1993 & 299.1993 \\
\hline$P_{4}$ & 159.6399 & 159.4680 & 159.73 & 159.7334 & 159.73310011396 & 159.7331 & 159.7331 \\
\hline$P_{5}$ & 159.6560 & 159.1429 & 159.73 & 159.7331 & 159.73310011396 & 159.7331 & 159.7331 \\
\hline$P_{6}$ & 158.4831 & 159.2724 & 159.73 & 159.7330 & 159.73310011396 & 159.7331 & 159.7331 \\
\hline$P_{7}$ & 159.6749 & 159.5371 & 159.73 & 159.7324 & 159.73310011396 & 159.7331 & 159.7331 \\
\hline$P_{8}$ & 159.7265 & 158.8522 & 159.73 & 159.7329 & 159.73310011396 & 159.7331 & 159.7331 \\
\hline$P_{9}$ & 159.6653 & 159.7845 & 159.73 & 159.7331 & 159.73310011396 & 159.7331 & 159.7331 \\
\hline$P_{10}$ & 114.0334 & 110.9618 & 114.80 & 107.4875 & 107.48435537177 & 107.4843 & 107.4844 \\
\hline$P_{11}$ & 75.0000 & 75.0000 & 75.00 & 75.0000 & 75.00000000000 & 75.0000 & 75.0000 \\
\hline$P_{12}$ & 60.0000 & 60.0000 & 60.00 & 60.0000 & 60.00000000000 & 60.0000 & 60.0000 \\
\hline$P_{13}$ & 87.5884 & 91.6401 & 92.40 & 92.3994 & 92.39991254274 & 92.3999 & 92.3999 \\
\hline Total power output (MW) & 2520.0000 & 2520.0000 & 2520.00 & 2519.9999 & 2520.000000000 & 2520.0000 & 2520.0000 \\
\hline Total fuel cost $(\$ / \mathrm{hr})$ & 24266.440 & 24261.050 & 24261.69 & 24252.950 & 24252.936305152 & 24252.9362294 & 24252.9363 \\
\hline \multicolumn{7}{|c|}{ Simulation times of the SOS algorithm (s) } & 62.6591 \\
\hline
\end{tabular}

Table 9. Results obtained from SOS for Test Case 5.

\begin{tabular}{|c|c|c|c|c|c|c|c|}
\hline Unit & SOS & Unit & SOS & Unit & SOS & Unit & SOS \\
\hline$P_{1}$ & 110.7998 & P11 & 94.0000 & $\mathrm{P} 21$ & 523.2794 & P31 & 190.0000 \\
\hline$P_{2}$ & 110.7998 & P12 & 94.0000 & P22 & 523.2794 & P32 & 190.0000 \\
\hline$P_{3}$ & 97.3999 & $\mathrm{P} 13$ & 214.7598 & $\mathrm{P} 23$ & 523.2794 & P33 & 190.0000 \\
\hline$P_{4}$ & 179.7331 & P14 & 394.2794 & P24 & 523.2794 & P34 & 164.7998 \\
\hline$P_{5}$ & 87.7999 & $\mathrm{P} 15$ & 394.2794 & P 25 & 523.2794 & P35 & 194.3978 \\
\hline$P_{6}$ & 140.0000 & $\mathrm{P} 16$ & 394.2794 & P26 & 523.2794 & P36 & 200.0000 \\
\hline$P_{7}$ & 259.5997 & P17 & 489.2794 & $\mathrm{P} 27$ & 10.0000 & P37 & 110.0000 \\
\hline$P_{8}$ & 284.5997 & P18 & 489.2794 & P28 & 10.0000 & P38 & 110.0000 \\
\hline$P_{9}$ & 284.5997 & P19 & 511.2794 & P29 & 10.0000 & P39 & 110.0000 \\
\hline$P_{10}$ & 130.0000 & P20 & 511.2794 & P30 & 87.7999 & $\mathrm{P} 40$ & 511.2794 \\
\hline \multicolumn{7}{|c|}{ Total power output (MW) } & 10500.000 \\
\hline \multicolumn{6}{|c|}{ Total fuel cost $(\$ / \mathrm{hr})$} & \multicolumn{2}{|r|}{121412.5355} \\
\hline \multicolumn{7}{|c|}{ Simulation times of the SOS algorithm (s) } & 105.8743 \\
\hline
\end{tabular}




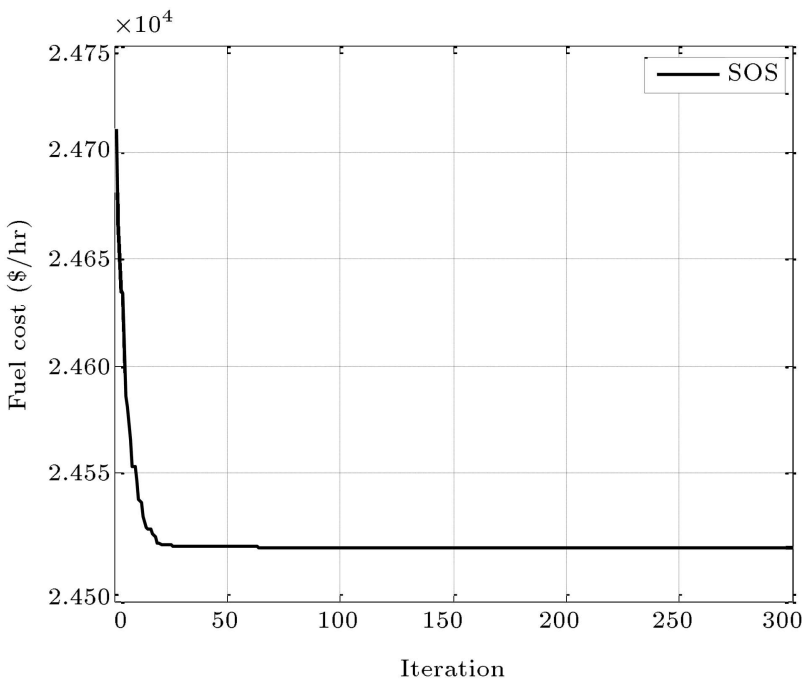

Figure 11. Convergence of total fuel cost obtained from SOS for 2520 MW load demand.

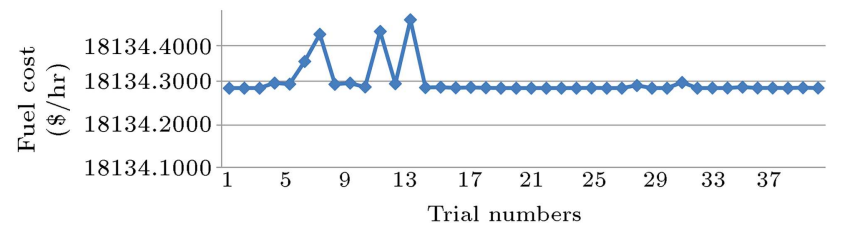

Figure 12. The total fuel cost values obtained from the SOS method for 40 trials (for $1800 \mathrm{MW}$ ).

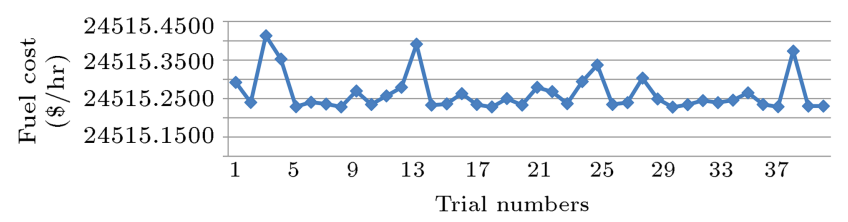

Figure 13. The total fuel cost values obtained from the SOS method for 40 trials (for $2520 \mathrm{MW}$ ).

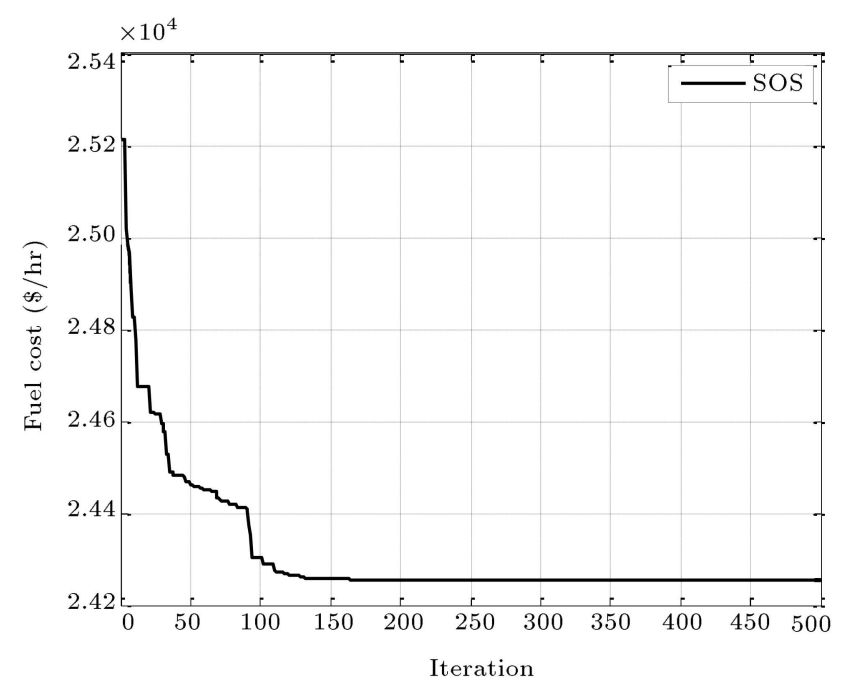

Figure 14. Convergence of total fuel cost obtained from SOS for 2520 MW constrained load demand.

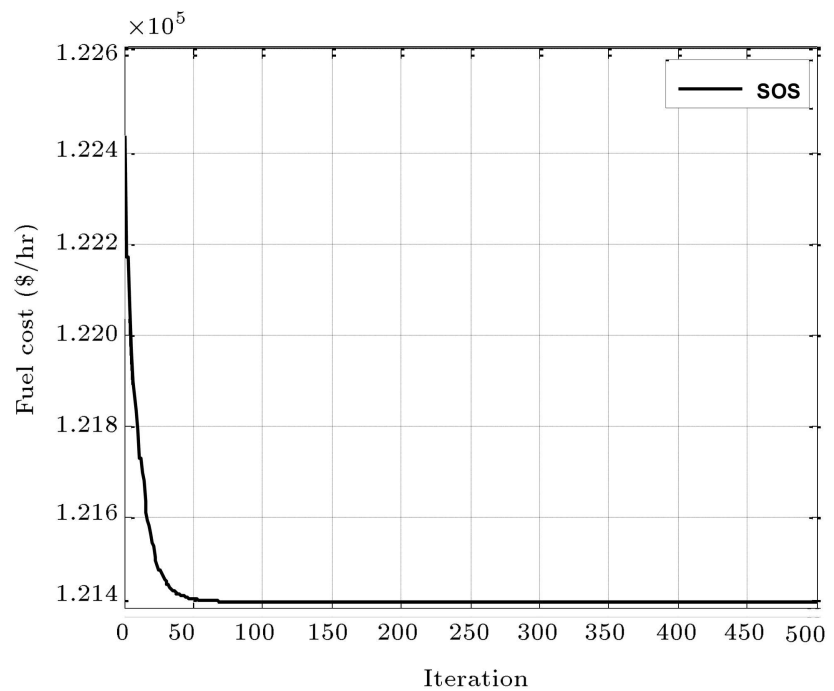

Figure 15. Convergence of total fuel cost obtained from SOS for Test Case 5.

tained from different methods in the literature, provided in Table 10. It can be seen in Table 10 that the proposed algorithm has the lowest fuel cost function with $121412.5355 \$ / \mathrm{hr}$ among all methods, which is the best value produced up to now. The convergence curve of the total fuel cost obtained from SOS is shown in Figure 15. The optimal solution is found after about 50 iterations as seen in Figure 15.

\section{Conclusion}

This paper has employed SOS algorithm for the ELD problem with valve-point effect, which is one of the important optimization problems in power systems. The proposed algorithm was examined on 3-machine 6-bus, IEEE 5-machine 14-bus, IEEE 6-machine 30bus, and 13- and 40-unit test systems both with transmission loss and without transmission loss. Obtained results showed that SOS algorithm solved the ELD problem successfully and effectively. From this comparative study, it could be concluded that the proposed algorithm could be effectively used to solve different types of ELD problems. In order to prove feasibility of the proposed method, results obtained from SOS were compared with other methods existing in the literature. According to the comparisons, the proposed algorithm reduced the total fuel cost values for 5-machine 14-bus system with $210 \mathrm{MW}$ load demand by $6.99 \$ / \mathrm{hr}$, for 5-machine 14-bus system with $259 \mathrm{MW}$ load demand by $0.99 \$ / \mathrm{hr}$ (the results of SOS for 6-machine 30bus system are same as the result of FPSOGSA), for 13-machine system with 1800 MW load demand by $2.669 \$ / \mathrm{hr}$, for $13-$ machine system with $2520 \mathrm{MW}$ load demand by $1.419 \$ / \mathrm{hr}$, and for 40-machine system with $10500 \mathrm{MW}$ load demand by $0.00661 \$ / \mathrm{hr}$. It could be clearly seen from the results that SOS produced better 
Table 10. Comparison of results for Test Case 5.

\begin{tabular}{|c|c|c|c|}
\hline Method & $\begin{array}{c}\text { Minimum cost } \\
(\$ / h r)\end{array}$ & $\begin{array}{c}\text { Average cost } \\
(\$ / \mathrm{hr})\end{array}$ & $\begin{array}{c}\text { Maximum Cost } \\
(\$ / h r)\end{array}$ \\
\hline HGPSO [40] & 124797.13 & 126855.70 & NA \\
\hline SPSO [40] & 124350.40 & 126074.40 & NA \\
\hline PSO [34] & 123930.45 & 124154.49 & NA \\
\hline CEP [39] & 123488.29 & 124793.48 & 126902.89 \\
\hline HG APSO [40] & 122780.00 & 124575.70 & NA \\
\hline FEP [39] & 122679.71 & 124119.37 & 127245.59 \\
\hline MFEP [39] & 122647.57 & 123489.74 & 124356.47 \\
\hline IFEP [39] & 122624.35 & 123382.00 & 125740.63 \\
\hline TM [21] & 122477.78 & 123078.21 & 124693.81 \\
\hline EP-SQP [34] & 122323.97 & 122379.63 & NA \\
\hline MPSO [10] & 122252.26 & NA & NA \\
\hline ESO [41] & 122122.16 & 122524.07 & 123143.07 \\
\hline HPSOM [40] & 122112.40 & 124350.87 & NA \\
\hline PSO-SQP [34] & 122094.67 & 122245.25 & NA \\
\hline GA_MU [42] & 122000.2837 & NA & NA \\
\hline Improved GA [43] & 121915.93 & 122811.41 & 123334.00 \\
\hline HPSOWM [40] & 121915.30 & 122844.40 & NA \\
\hline IGAMU [42] & 121819.25 & NA & NA \\
\hline HDE [44] & 121813.26 & 122705.66 & NA \\
\hline PSO $[45]$ & 121735.4736 & 122513.9175 & 123467.4086 \\
\hline $\operatorname{APSO}(1)[45]$ & 121704.7391 & 122221.3697 & 122995.0976 \\
\hline ST-HDE [44] & 121698.51 & 122304.30 & NA \\
\hline NPSO-LRS [46] & 121664.43 & 122209.31 & 122981.59 \\
\hline $\operatorname{APSO}(2)[45]$ & 121663.5222 & 122153.6730 & 122912.3958 \\
\hline $\operatorname{MTS}[47]$ & 121532.10 & 121798.51 & 122022.15 \\
\hline SOH_PSO [48] & 121501.14 & 121853.57 & 122446.30 \\
\hline CPSO-SQP [49] & 121458.54 & 122028.16 & NA \\
\hline GA_PS_SQP [50] & 121458.14 & 122039.00 & NA \\
\hline $\mathrm{BBO}[17]$ & 121426.9530 & 121508.0325 & 121688.6634 \\
\hline PSO_MSAF [51] & 121423.23 & NA & NA \\
\hline $\mathrm{DE} / \mathrm{BBO}[52]$ & 121420.8948 & 121420.8952 & 121420.8963 \\
\hline FAPSO-NM [26] & 121418.30 & 121418.8030 & 121419.80 \\
\hline HGA [53] & 121418.27 & 121784.04 & NA \\
\hline FA [23] & 121415.05 & 121416.57 & 121424.56 \\
\hline MDE [54] & 121414.79 & 121418.44 & 121466.04 \\
\hline IPSO-TVAC [55] & 121412.5450 & 121419.30 & 121423.80 \\
\hline FPSOGSA [35] & 121412.542110 & 121413.561938 & 121414.983790 \\
\hline SOS & 121412.5355 & 121413.2597 & 121413.9281 \\
\hline
\end{tabular}


results than other well-known meta-heuristic methods for both small and big test systems. Moreover, the proposed approach has some merits such as simple concept, easy implementation, and better effectiveness than previous methods.

\section{References}

1. Farag, A., Al-Baiyat, S., and Cheng, T.C. "Economic load dispatch multiobjective optimization procedures using linear programming techniques", IEEE Trans Power Syst, 10(2), pp. 731-738 (1995).

2. Vargas, L.S., Quintana, V.H., and Vannelli, A. "A tutorial description of an interior point method and its applications to security-constrained economic dispatch", Power Systems, IEEE Transactions on , 8(3), pp. 1315-1324 (1993).

3. Irisarri, G., Kimball, L.M., Clements, K.A., Bagchi, A., and Davis, P.W. "Economic dispatch with network and ramping constraints via interior point methods", Power Systems, IEEE Transactions on , 13(1), pp. 236-242 (1998).

4. Liang, Z.-X. and Duncan Glover, J. "A zoom feature for a dynamic programming solution to economic dispatch including transmission losses", Power Systems, IEEE Transactions on, 7(2), pp. 544-550 (1992).

5. Wong, K.P. and Fung, C.C. "Simulated annealing based economic dispatch algorithm", IEE Proceedings $C$ (Generation, Transmission and Distribution), IEE, 140(6), pp. 509-515 (1993).

6. Walters, D.C. and Sheble, G.B. "Genetic algorithm solution of economic dispatch with valve point loading", Power Systems, IEEE Transactions on, 8(3), pp. 13251332 (1993).

7. Chiang, C.L. "Improved genetic algorithm for power economic dispatch of units with valve-point effects and multiple fuels", Power Systems, IEEE Transactions on, 20(4), pp. 1690-1699 (2005).

8. Lin, W.H., Cheng, F.S., and Tsay, M.T. "An improved tabu search for economic dispatch with multiple minima", Power Systems, IEEE Transactions on, 17(1), pp. 108-112 (2002).

9. Gaing, Z.L. "Particle swarm optimization to solving the economic dispatch considering the generator constraints", Power Systems, IEEE Transactions on, 18(3), pp. 1187-1195 (2003).

10. Park, J.B., Lee, K.S., Shin, J.R., and Lee, K.Y. "A particle swarm optimization for economic dispatch with nonsmooth cost functions", Power Systems, IEEE Transactions on, 20(1), pp. 34-42 (2005).

11. Noman, N. and Iba, H. "Differential evolution for economic load dispatch problems", Electric Power Systems Research, 78(8), pp. 1322-1331 (2008).

12. Hou, Y.H., Wu, Y.W., Lu, L.J., and Xiong, X.Y. "Generalized ant colony optimization for economic dispatch of power systems", In International Conference on Power System Technology, pp. 225-229 (2002).
13. Pothiya, S., Ngamroo, I., and Kongprawechnon, W. "Ant colony optimisation for economic dispatch problem with non-smooth cost functions", International Journal of Electrical Power \& Energy Systems, 32(5), pp. 478-487 (2010).

14. Panigrahi, B.K. and Pandi, V.R. "Bacterial foraging optimisation: Nelder-Mead hybrid algorithm for economic load dispatch", IET Generation, Transmission \& Distribution, 2(4), pp. 556-565 (2008).

15. Hemamalini, S. and Simon, S.P. "Artificial bee colony algorithm for economic load dispatch problem with non-smooth cost functions", Electric Power Components and Systems, 38(7), pp. 786-803 (2010).

16. Duman, S., Güvenç, U., and Yörükeren, N. "Gravitational search algorithm for economic dispatch with valve-point effects", International Review of Electrical Engineering, 5(6), pp. 2890-2895 (2010).

17. Bhattacharya, A. and Chattopadhyay, P.K. "Biogeography-based optimization for different economic load dispatch problems", Power Systems, IEEE Transactions on, 25(2), pp. 1064-1077 (2010).

18. Han, F. and Lu, Q.S. "An improved chaos optimization algorithm and its application in the economic load dispatch problem", International Journal of Computer Mathematics, 85(6), pp. 969-982 (2008).

19. Al-Sumait, J.S., Al-Othman, A.K., and Sykulski, J.K. "Application of pattern search method to power system valve-point economic load dispatch", International Journal of Electrical Power \& Energy Systems, 29(10), pp. $720-730$ (2007).

20. Shaw, B., Mukherjee, V., and Ghoshal, S.P. "Seeker optimisation algorithm: application to the solution of economic load dispatch problems", IET Generation, Transmission \& Distribution, 5(1), pp. 81-91 (2011).

21. Liu, D. and Cai, Y. "Taguchi method for solving the economic dispatch problem with nonsmooth cost functions", Power Systems, IEEE Transactions on, 20(4), pp. 2006-2014 (2005).

22. Narimani, M.R. "A new modified shuffle frog leaping algorithm for non-smooth economic dispatch", World Applied Sciences Journal, 12(6), pp. 803-814 (2011).

23. Yang, X.S., Sadat Hosseini, S.S., and Gandomi, A.H. "Firefly algorithm for solving non-convex economic dispatch problems with valve loading effect", Applied Soft Computing, 12(3), pp. 1180-1186 (2012).

24. Coelho, L.D.S. and Mariani, V.C. "An efficient cultural self-organizing migrating strategy for economic dispatch optimization with valve-point effect", Energy Conversion and Management, 51(12), pp. 2580-2587 (2010). 
25. Coelho, L.D.S. and Mariani, V.C. "Combining of chaotic differential evolution and quadratic programming for economic dispatch optimization with valvepoint effect", Power Systems, IEEE Transactions on, 21(2), pp. 989-996 (2006).

26. Niknam, T. "A new fuzzy adaptive hybrid particle swarm optimization algorithm for non-linear, nonsmooth and non-convex economic dispatch problem", Applied Energy, 87(1), pp. 327-339 (2010).

27. He, D., Wang, F., and Mao, Z. "A hybrid genetic algorithm approach based on differential evolution for economic dispatch with valve-point effect", International Journal of Electrical Power \& Energy Systems, 30(1), pp. 31-38 (2008).

28. Mirjalili, S. and Hashim, S.Z.M. "A new hybrid PSOGSA algorithm for function optimization", In International Conference on Computer and Information Application (ICCIA 2010), pp. 374-377 (2010).

29. Malik, T.N., ul Asar, A., Wyne, M.F., and Akhtar, S. "A new hybrid approach for the solution of nonconvex economic dispatch problem with valve-point effects", Electr Power Syst Res, 80, pp. 1128-1136 (2010).

30. Yasar, C. and Özyön, S. "A new hybrid approach for nonconvex economic dispatch problem with valvepoint effect", Energy, 35, pp. 5838-5845 (2011).

31. Reddy, A.S. and Vaisakh, K. "Shuffled differential evolution for large scale economic dispatch", Electr Power Syst Res, 96, pp. 237-245 (2013).

32. Reddy, A.S. and Vaisakh, K. "Shuffled differential evolution for economic dispatch with valve point loading effects", Int J Electr Power Energy Syst, 46, pp. 342352 (2013).

33. Vlachogiannis, J.G. and Lee, K.Y. "Economic load dispatch - A comparative study on heuristic optimization techniques with an improved coordinated aggregation based PSO", IEEE Trans Power Syst, 24(2), pp. 9911001 (2009).

34. Victoire, T.A.A. and Jeyakumar, A.E. "Hybrid PSOSQP for economic dispatch with valve-point effect", Electr Power Syst Res, 71(1), pp. 51-59 (2004).

35. Duman, S., Yorukeren, N., and Altas, I.H. "A novel modified hybrid PSOGSA based on fuzzy logic for nonconvex economic dispatch problem with valve-point effect", International Journal of Electrical Power \& Energy Systems, 64, pp. 121-135 (2015).

36. Babu, G.S.S., Das, D.B., and Patvardhan, C. "Real parameter quantum evolutionary algorithm for economic load dispatch", IET Gener Transm Distrib, 2(1), pp. 22-31 (2008).

37. Meng, K., Wang, H.G., Dong, Z., and Wong, K.P. "Quantum-inspired particle swarm optimization for valve-point economic load dispatch", Power Systems, IEEE Transactions on, 25(1), pp. 215-222 (2010).
38. Cheng, M.Y. and Prayogo, D. "Symbiotic Organisms Search: A new metaheuristic optimization algorithm", Computers \& Structures, 139, pp. 98-112 (2014).

39. Sinha, N., Chakrabarti, R., and Chattopadhyay, P.K. "Evolutionary programming techniques for economic load dispatch", IEEE Trans Evol Comput, 7(1), pp. 83-94 (2003).

40. Ling, S.H., Lu, H.H.C., Chan, K.Y., Lam, H.K., Yeung, B.C.W., and Leung, F.H. "Hybrid particle swarm optimization with wavelet mutation and its industrial applications", IEEE Trans Syst Man Cybern Part B: Cybern, 38(3), pp. 743-763 (2008).

41. Pereira-Neto, A., Unsihuay, C., and Saavedra, O.R. "Efficient evolutionary strategy optimization procedure to solve the nonconvex economic dispatch problem with generator constraints", IEE Proc Gener Transm Distrib, 152(5), pp. 653-660 (2005).

42. Chiang, C.L. "Genetic-based algorithm for economic load dispatch", IET Gener Transm Distrib, 1(2), pp. 261-269 (2007).

43. Ling, S.H. and Leung, F.H.F. "An improved genetic algorithm with average-bound crossover and wavelet mutation operation", Soft Comput, 11(1), pp. 7-31 (2007).

44. Wang, S.K., Chiou, J.P., and Liu, C.W. "Nonsmooth/non-convex economic dispatch by a novel hybrid differential evolution algorithm", IET Gener Transm Distrib, 1(5), pp. 793-803 (2007).

45. Selvakumar, A.I. and Thanushkodi, K. "Antipredatory particle swarm optimization: Solution to nonconvex economic dispatch problems", Electr Power Syst Res, 78, pp. 2-10 (2008).

46. Selvakumar, L. and Thanushkodi, K. "A new particle swarm optimization solution to nonconvex economic dispatch problems", IEEE Trans Power Syst, 22(1), pp. $42-51$ (2007).

47. Sa-ngiamvibool, W., Pothiya, S., and Ngamro, I. "Multiple tabu search algorithm for economic dispatch problem considering valve-point effects", Electr Power Energy Syst, 33, pp. 846-854 (2011).

48. Chaturvedi, K.T., Pandit, M., and Srivastava, L. "Selforganizing hierarchical particle swarm optimization for nonconvex economic dispatch", IEEE Trans Power Syst, 23(3), pp. 1079-1087 (2008).

49. Cai, J., Li, Q., Li, L., Peng, H., and Yang, Y. "A hybrid CPSO-SQP method for economic dispatch considering the valve-point effects", Energy Convers Manage, 53, pp. 175-81 (2012).

50. Alsumait, J.S., Sykulski, J.K., and Al-Othman, A.K. "A hybrid GA-PS-SQP method to solve power system valve-point economic dispatch problems", Appl Energy, 87, pp. 1773-1781 (2010). 
51. Subbaraj, P., Rengaraj, R., Salivahanan, S., and Senthilkumar, T.R. "Parallel particle swarm optimization with modified stochastic acceleration factors for solving large scale economic dispatch problem", Electr Power Energy Syst, 32, pp. 1014-1023 (2010).

52. Bhattacharya, A. and Chattopadhyay, P.K. "Hybrid differential evolution with biogeography-based optimization for solution of economic load dispatch", IEEE Trans Power Syst, 25(4), pp. 1955-1964 (2010).

53. Dakuo, H., Fuli, W., and Zhizhong, M. "A hybrid genetic algorithm approach based on differential evolution for economic dispatch with valve-point effect", Electr Power Energy Syst, 30, pp. 31-38 (2008).

54. Amjady, N. and Sharifzadeh, H. "Solution of non- convex economic dispatch problem considering valve loading effect by a new modified differential evolution algorithm", Electr Power Energy Syst, 32, pp. 893-903 (2010).

55. Mohammadi-Ivatloo, B., Rabiee, A., Soroudi, A., and Ehsan, M. "Iteration PSO with time varying acceleration coefficients for solving non-convex economic dispatch problems", Int $J$ Electr Power Energy Syst, 42, pp. 508-516 (2012).

\section{Appendix}

Tables A.1.to A.5 are described as data of the test cases.

Table A.1. Setting parameters of the SOS algorithm for the ELD problem.

\begin{tabular}{lcc}
\hline \multicolumn{1}{c}{ Test system } & $\begin{array}{c}\text { Number of organisms } \\
\text { (eco_size) }\end{array}$ & max_iter \\
\hline 6-bus 3-machine system & 50 & 100 \\
IEEE 14-bus 5-machine system & 50 & 100 \\
IEEE 30-bus 6-machine system & 50 & 200 \\
13-unit test system (for 1800 MW and 2520 MW) & 80 & 300 \\
13-unit test system (for 2520 MW constrained ) & 100 & 500 \\
40-unit test system & 100 & 500 \\
\hline
\end{tabular}

Table A.2. Cost coefficients of the generating units [29,34].

\begin{tabular}{|c|c|c|c|c|c|c|c|c|c|}
\hline & Test system & Bus & $a$ & $b$ & $c$ & $d$ & $e$ & $P^{\min }$ & $P^{\max }$ \\
\hline \multirow{3}{*}{1} & \multirow{3}{*}{ 6-bus 3-machine system } & 1 & 213.1 & 11.669 & 0.00533 & 130 & 0.0635 & 50 & 200 \\
\hline & & 2 & 200.0 & 10.333 & 0.00889 & 90 & 0.0598 & 37.5 & 150 \\
\hline & & 3 & 240.0 & 10.833 & 0.00741 & 100 & 0.0685 & 45 & 180 \\
\hline \multirow{5}{*}{2} & \multirow{5}{*}{ IEEE 14-bus 5-machine system } & 1 & 150.0 & 2.00 & 0.0016 & 50.0 & 0.0630 & 50 & 200 \\
\hline & & 2 & 25.0 & 2.50 & 0.0100 & 40.0 & 0.0980 & 20 & 80 \\
\hline & & 3 & 0.0 & 1.00 & 0.0625 & 0.0 & 0.0 & 15 & 50 \\
\hline & & 6 & 0.0 & 3.25 & 0.00834 & 0.0 & 0.0 & 10 & 35 \\
\hline & & 8 & 0.0 & 3.00 & 0.025 & 0.0 & 0.0 & 10 & 30 \\
\hline \multirow{6}{*}{3} & \multirow{6}{*}{ IEEE 30-bus 6-machine system } & 1 & 150.0 & 2.00 & 0.0016 & 50.0 & 0.0630 & 50 & 200 \\
\hline & & 2 & 25.0 & 2.50 & 0.0100 & 40.0 & 0.0980 & 20 & 80 \\
\hline & & 5 & 0.0 & 1.00 & 0.0625 & 0.0 & 0.0 & 15 & 50 \\
\hline & & 8 & 0.0 & 3.25 & 0.00834 & 0.0 & 0.0 & 10 & 35 \\
\hline & & 11 & 0.0 & 3.00 & 0.025 & 0.0 & 0.0 & 10 & 30 \\
\hline & & 13 & 0.0 & 3.00 & 0.025 & 0.0 & 0.0 & 12 & 40 \\
\hline
\end{tabular}


Table A.3. B-coefficients for test systems [29,34].

1 6-bus 3-machine system

$$
[B]=\left[\begin{array}{ccc}
0.0552 & 0.0062 & -0.0046 \\
0.0062 & 0.0253 & 0.0064 \\
-0.0046 & 0.0064 & 0.0286
\end{array}\right]
$$

$$
\begin{aligned}
{\left[B_{0}\right.} & =\left[\begin{array}{lll}
0.0046 & 0.0035 & 0.0019
\end{array}\right] \\
B_{00} & =0.00055711
\end{aligned}
$$

2 IEEE 14 -bus 5-machine system

$$
\begin{aligned}
{[B] } & =\left[\begin{array}{ccccc}
0.0212 & 0.0085 & -0.0009 & 0.0021 & 0.0007 \\
0.0085 & 0.0206 & -0.0041 & 0.0037 & 0.0001 \\
-0.0009 & -0.0041 & 0.0395 & -0.0207 & -0.0251 \\
0.0021 & 0.0037 & -0.0207 & 0.0613 & -0.0071 \\
0.0007 & 0.0001 & -0.0251 & -0.0071 & 0.0406
\end{array}\right] \\
{\left[B_{0}\right] } & =\left[\begin{array}{lllll}
-0.0002 & 0.0030 & -0.0017 & 0.0101 & -0.0038
\end{array}\right] \\
B_{00} & =0.00085357
\end{aligned}
$$

3 IEEE 30-bus 6-machine system

$$
\begin{aligned}
& {[B]=\left[\begin{array}{cccccc}
0.0224 & 0.0103 & 0.0016 & -0.0053 & 0.0009 & -0.0013 \\
0.0103 & 0.0158 & 0.0010 & -0.0074 & 0.0007 & 0.0024 \\
0.0016 & 0.0010 & 0.0474 & -0.0687 & -0.0060 & -0.0350 \\
-0.0053 & -0.0074 & -0.0687 & 0.3464 & 0.0105 & 0.0534 \\
0.0009 & 0.0007 & -0.0060 & 0.0105 & 0.0119 & 0.0007 \\
-0.0013 & 0.0024 & -0.0350 & 0.0534 & 0.0007 & 0.2353
\end{array}\right]} \\
& {\left[B_{0}\right]=\left[\begin{array}{llllll}
-0.0005 & 0.0016 & -0.0029 & 0.0060 & 0.0014 & 0.0015
\end{array}\right]} \\
& B_{00}=0.0011
\end{aligned}
$$

Table A.4. Generators data of Test Case 4 [35].

\begin{tabular}{ccccccccc}
\hline $\begin{array}{c}\text { Test } \\
\text { system }\end{array}$ & Units & $\boldsymbol{a}$ & $\boldsymbol{b}$ & $\boldsymbol{c}$ & $\boldsymbol{d}$ & $\boldsymbol{e}$ & $\boldsymbol{P}^{\text {min }}$ & $\boldsymbol{P}^{\text {max }}$ \\
\hline & 1 & 550 & 8.10 & 0.00028 & 300 & 0.035 & 0 & 680 \\
& 2 & 309 & 8.10 & 0.00056 & 200 & 0.042 & 0 & 360 \\
& 3 & 307 & 8.10 & 0.00056 & 200 & 0.042 & 0 & 360 \\
& 4 & 240 & 7.74 & 0.00324 & 150 & 0.063 & 60 & 180 \\
& 5 & 240 & 7.74 & 0.00324 & 150 & 0.063 & 60 & 180 \\
& 6 & 240 & 7.74 & 0.00324 & 150 & 0.063 & 60 & 180 \\
& 7 & 240 & 7.74 & 0.00324 & 150 & 0.063 & 60 & 180 \\
& 8 & 240 & 7.74 & 0.00324 & 150 & 0.063 & 60 & 180 \\
& 9 & 240 & 7.74 & 0.00324 & 150 & 0.063 & 60 & 180 \\
& 10 & 126 & 8.60 & 0.00284 & 100 & 0.084 & 40 & 120 \\
& 11 & 126 & 8.60 & 0.00284 & 100 & 0.084 & 40 & 120 \\
& 12 & 126 & 8.60 & 0.00284 & 100 & 0.084 & 55 & 120 \\
& 13 & 126 & 8.60 & 0.00284 & 100 & 0.084 & 55 & 120 \\
\hline
\end{tabular}


Table A.5. B-coefficients for 13 -unit test system [31,35].

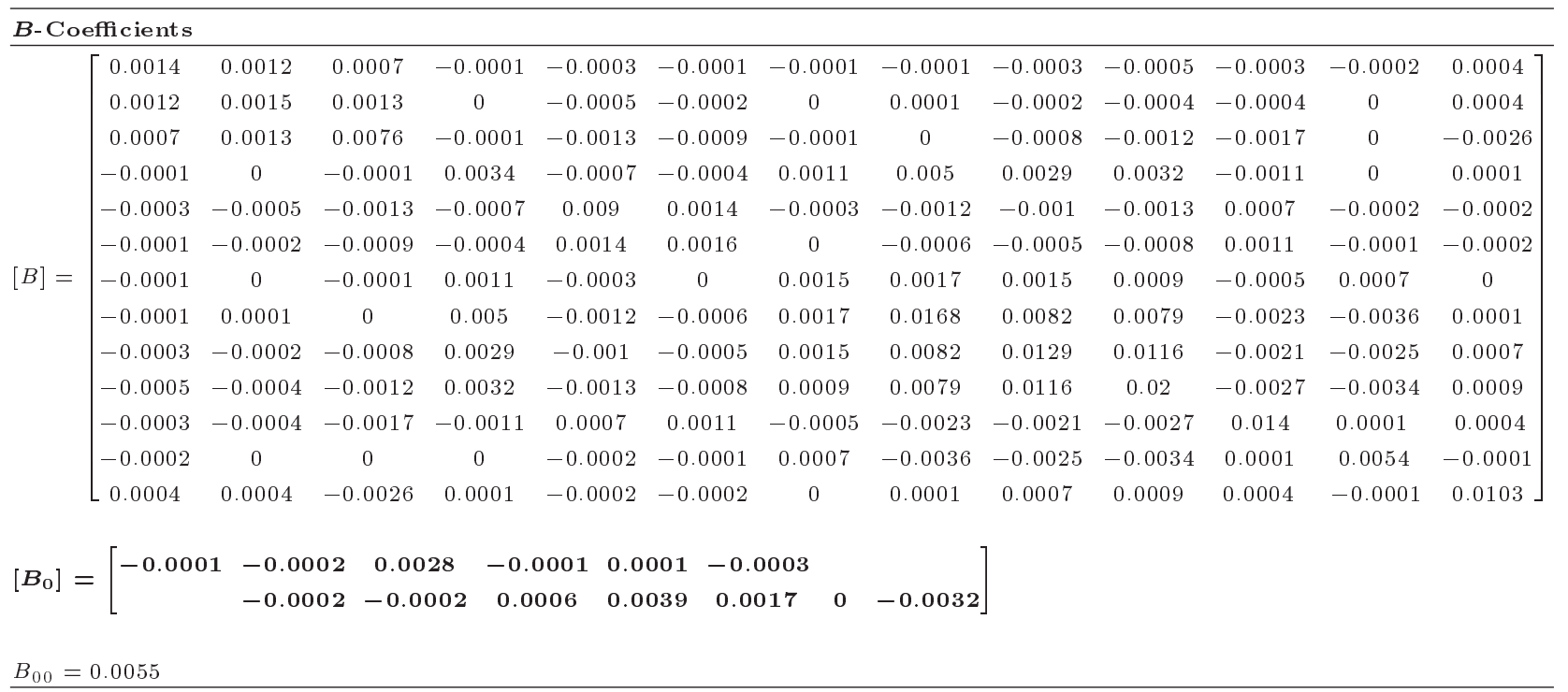

\section{Biographies}

Ugur Guvenc was born in Zile, Turkey, in 1980. He received the BS degree in Electrical Education from Abant İzzet Baysal University, Bolu, Turkey, in 2002, and the MS and $\mathrm{PhD}$ degrees from Gazi University, Turkey, in 2005 and 2008, respectively. He is currently Associate Professor in the Department of Electrical and Electronics Engineering in the Faculty of Technology at Duzce University, Turkey. His main research interests are artificial intelligence, power systems, and image processing.

Serhat Duman was born in Bandırma, Turkey, in 1981. He received the BS degree in Electrical Education from Abant İzzet Baysal University, Bolu, Turkey, in 2008, the MS degree from the Department of Electrical Education at Duzce University, Turkey, in 2010, and the PhD degree from the Department of Electrical Engineering at Kocaeli University, Turkey, in 2015. He is currently Assistant Professor in the Department of Electrical and Electronics Engineering in the Faculty of Technology at Duzce University, Turkey. His areas of research include power system stability, FACTS, optimization techniques, optimization problems in power systems, renewable energy resources, and artificial intelligence.

Yusuf Sonmez was born in Ankara, Turkey, in 1980. He received the BS degree in Electrical Education from Gazi University, Turkey, in 2002. Also, he received MS and PhD degrees in 2005 and 2008 from Gazi University, where he has been working as Associate Professor since 2014. His research interests are artificial intelligence, optimization methods, power system stability, and FACTS devices.
Hamdi Tolga Kahraman received the BS and the $\mathrm{PhD}$ degrees from the Institute of Science and Technology at Gazi University, Turkey, in 2004 and 2009, respectively. He worked as a scholar visitor and researcher in Ford Interdisciplinary Research Center at North Carolina A\&T State University, USA, in 2012. He is now Associate Professor and head of the Department of Software Engineering at Karadeniz Technical University. His research interests include modern heuristic and intuitive optimization techniques (genetic algorithms, artificial bee colony algorithm, and symbiotic organism search), artificial neural networks, hybrid classification and estimation algorithms, searching algorithms, data mining, fuzzy logic, intelligent systems, user modeling, hypermedia reference models, human-computer interaction, and web-based smart applications. He is an editorial board member of Algorithms Research and International Journal of Renewable Energy Research-IJRER, and program committee member of numerous international conferences. He received his first patent on a supervised adaptive hypermedia system.

Mehmet Kenan Dosoglu was born in Gaziantep, Turkey, in 1983. He received the BS degree in Electrical Education from Abant Izzet Baysal University, Bolu, Turkey, in 2006, the MS degree from the Department of Electrical Education at Duzce University, Turkey, in 2010, and the PhD degree from the Department of Electrical Engineering at Kocaeli University, Turkey, in 2014. He is currently Assistant Professor in the Department of Electrical and Electronics Engineering in the Faculty of Technology at Duzce University, Turkey. His areas of research include power system stability, FACTS devices, and wind farm dynamic modelling. 